\title{
Corrosion Behavior of Reinforcing Steel in Concrete Elements in Alkaline Medium
}

\author{
Bourenane $\mathrm{N}^{1}{ }^{*}$, Sedira N${ }^{2}$, Hamlaoui $\mathrm{Y}^{1}$
}

1 University of Mohamed Chérif Messaadia, Dept. Process Engineering, LPMR Lab., Rue d'annaba, BP 1553, 41000 Souk-Ahras, Algeria

2 Univ Souk Ahras. Fac Sci and Tech. Dept Material Sciences. Rue d'Annaba. BP 1553. 41000 Souk-Ahras. Algeria

* Corresponding Author: bourenane_nadjette1990@yahoo.fr

Received: 09-02-2018

Accepted: 24-05-2019

\begin{abstract}
Corrosion of steel in reinforcement concrete is complex. When chloride ions and oxygen reach reinforcing steel, corrosion is initiated. The deterioration process starts with expansions of the bare steel substrate then after cracks in the concrete are developed. The aim of this work is to determine firstly, through the electrochemical technic, the critical concentration of chloride ions which are responsible for the initiation of the dissolution step. Then, the effect of the external parameters on the rate of penetration of the chloride ions into the concrete are also evaluated. For this propose, the electrochemical behavior of the steel of construction "E24" is studied in carbonate medium without and with different concentrations of chloride ions. The effect of various parameters such as temperature, ions concentration and solution $\mathrm{pH}$ was also evaluated through the evolution of the open circuit potential, d.c polarization measurement and electrochemical impedance spectroscopy. The d.c polarization and EIS results shows that the addition of $0.5 \mathrm{M} \mathrm{CaCl}_{2}$ (as critical concentration) to the saturated $\mathrm{Ca}(\mathrm{OH})_{2}$ solution, brings to a rapid and a continuous dissolution of the substrate where after 3 hours of immersion time the whole surface of the substrate was covered the corrosion products. This is may be due to specific adsorption of Cl-.
\end{abstract}

Key words: Reinforcing Steel, d.c polarization, SIE, alkaline medium, chloride ions.

\section{Introduction}

The degradation phenomena and the damage of reinforced concrete structures depend on a large number of factors which intervene, not individually, but in a more or less complex relationship with each other: the nature and structure of the material, the environment and its chemical characteristics, the temperature, to which the material is subjected, the constraints imposed upon it. The coating concrete, or the mortar around an armature, offers the steels a double protection against corrosion. At first, it acts as a physical barrier that limits the penetration of aggressive agents and the access of oxygen to the framework. Then, thanks to the composition of the interstitial solution and its high $\mathrm{pH}$, between 12 and 13, the concrete offers a chemical protection against corrosion. Indeed, at this $\mathrm{pH}$ level, the reinforcing steels do not corrode because they are covered with a passive film with a thickness between 10-2 and 10-1 $\mu \mathrm{m}$, called "passive layer", most often formed with $\mathrm{Fe}_{3} \mathrm{O}_{4}-\gamma \mathrm{Fe}_{2} \mathrm{O}_{3}$. However, the porosity of the concrete is at the origin of the reduction of its capacity to isolate the steel from the aggressive substances of the external environment. Thus, in the presence of water and oxygen, the passive film is destroyed by various agents such as chlorides and carbon dioxide. The corrosion is then possible; there is a reduction in the sections of the steel and the formation of rust, the volume of which is at least twice as great as that of the lost steel. The accumulation of these corrosion products leads to the swelling and deformation of the coating, which eventually cracks the concrete or causes it to burst. A saturated solution of calcium hydroxide is usually used as a synthetic solution representative of the interstitial solution of the concretes in order to study the 
electrochemical behavior of metallic reinforcements (Kosmatka et al., 2004). However, the interstitial solution also contains other cations such as $\mathrm{Ca}^{2+}, \mathrm{Na}^{+}$and $\mathrm{K}^{+}$and anions such as $\mathrm{OH}^{-}$ and $\mathrm{SO}_{2}{ }^{-4}$. Sodium and potassium ions come from alkali metal oxides, such as $\mathrm{Na}_{2} \mathrm{O}$ and $\mathrm{K}_{2} \mathrm{O}$, present in the cement. As for the sulphate ions, they can come from the gypsum $\left(\mathrm{CaSO}_{4} \mathrm{H}_{2} \mathrm{O}\right)$ added during the cement manufacturing, agents of contaminants or the water used during the mixing (Rosenberg, 1989). It has also been shown that the quality of the oxide film formed on the surface of the steel depends, on the $\mathrm{pH}$ and the temperature, on the chemical composition of the solution and particularly on the presence of sulfate ions. The purpose of this work is to study the electrochemical corrosion behavior of the structural steel E24, generally used as a constituent material of metal reinforcements in construction concrete using stationary and nonstationary electrochemical techniques. During this study, two solutions were used to allow us to study the corrosion behavior of the mild steel in a representative environment, the phenomena of carbonation of concrete and to simulate the phenomena of penetration of chloride ions: Calcium hydroxide solution $\left(\mathrm{Ca}(\mathrm{OH})_{2}\right)$ saturated with a concentration of $\left.3 \mathrm{~g} / \mathrm{l}\right)$. Calcium hydroxide solution $\left(\mathrm{Ca}(\mathrm{OH})_{2}\right)$ with a concentration of $3 \mathrm{~g} / \mathrm{l}$ with different concentrations of $\mathrm{CaCl}_{2}$ (the concentration of $\mathrm{CaCl} 2$ changes when we study the influence of the chloride content). Thus, the influence of the other parameters such as agitation speed, the $\mathrm{pH}$ of the medium on corrosion, is elaborated in order to understand and propose the mechanism involved in this corrosion.

\section{Materials}

The studied material is a mild steel E24, generally used as a constituent material of metal reinforcements in construction concrete. The composition of the major elements of the steel E24 is represented in the following table:

Table 1. Chemical composition of E24 Steel.

\begin{tabular}{|c|c|}
\hline Element & \% max. \\
\hline \hline Carbon (C) & 0.17 \\
\hline Manganese (Mn) & 1.40 \\
\hline Phosphorus (P) & 0.045 \\
\hline Sulfur (S) & 0.045 \\
\hline Nitrogen (N) & 0.009 \\
\hline Iron (Fe) & The rest \\
\hline
\end{tabular}

\section{Samples preparation}

The working electrodes E24 are machined in the form of a spherical cut with a surface area of $1.33 \mathrm{~cm} 2$. The samples are then coated in epoxy resin. Only one side is active, and the other one is chemically covered with inert resin. In order to ensure electrical contact with the electrochemical assembly, a conductive wire has been welded to the end of the inactive surface. After that, the active surface of the electrode is polished to an abrasive grinding paper SiC varying between 180 and 2500. The surface is then cleaned in an ethanol solution before being dried by a stream of hot air. The quality of this preparation is important because the electrochemical corrosion measurements or the coating deposition measurements are sensitive at the surface state (Neville, 2000). In addition, it allows minimizing the presence of the surface heterogeneities.

\section{Electrochemical cell, aqueous synthesis solution}

The electrochemical tests are carried out in a conventional three electrode cell containing approximately $250 \mathrm{~mL}$ of solution (Fig. 1) : a working electrode in ordinary steel E24, a saturated calomel reference electrode $\left(\mathrm{Hg} / \mathrm{Hg}_{2} \mathrm{Cl}_{2} / \mathrm{KCl}\right.$ sat $)(\mathrm{E} 0 \mathrm{ECS}=+0.241 \mathrm{~V} / \mathrm{ENH})$ and an auxiliary electrode or counter electrode of platinum with a surface area of $1 \mathrm{~cm}^{2}$. 


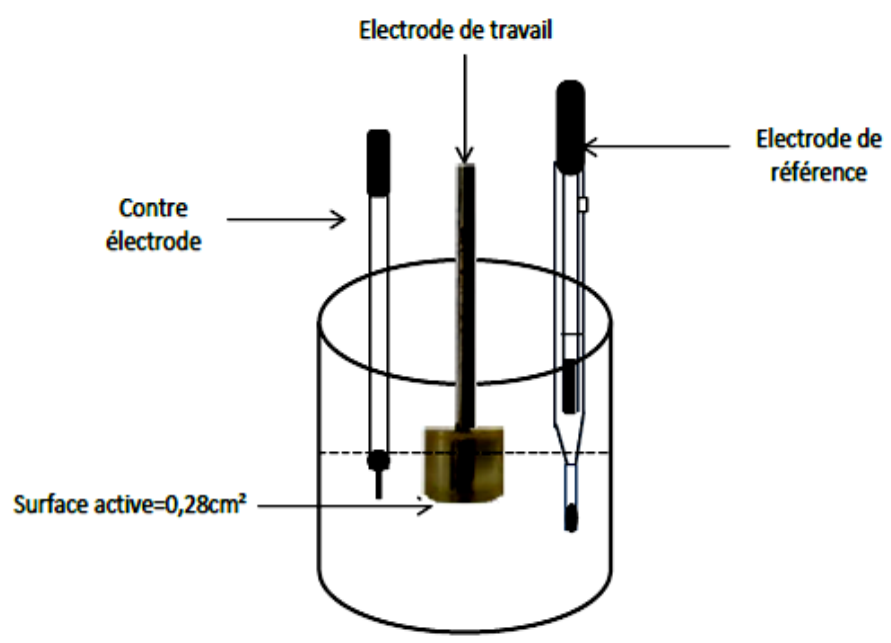

Fig. 1. Working cell used for the electrochemical study.

During this study, two solutions were used to allow us to study the corrosion behavior of the mild steel in a representative environment, the phenomena of carbonation of concrete and to simulate the phenomena of penetration of chloride ions

- Calcium hydroxide solution $\left(\mathrm{Ca}(\mathrm{OH})_{2}\right)$ saturated with a concentration of $\left.3 \mathrm{~g} / \mathrm{l}\right)$.

- Calcium hydroxide solution $\left(\mathrm{Ca}(\mathrm{OH})_{2}\right)$ with a concentration of $3 \mathrm{~g} / \mathrm{l}$ with different concentrations of $\mathrm{CaCl}_{2}$ (the concentration of $\mathrm{CaCl}_{2}$ changes when we study the influence of the chloride content).

\section{Electrochemical characterization of the corrosion of structural steel E24}

\subsection{Evolution of corrosion potential}

The electrochemical experiments were carried out using a potentiostat (Bio-Logic 150) piloted by the software ECLab, version 10.40. The principle of this test is to immerse the electrode of the steel E24 in both $\mathrm{Ca}(\mathrm{OH})_{2}$ solution and $\mathrm{Ca}(\mathrm{OH})_{2}$ solution with $0.5 \mathrm{M}$ of $\mathrm{CaCl}_{2}$ and to follow the spontaneous evolution of the corrosion potential as a function of time. This test may take several hours until the corrosion potential stabilizes (Fig. 2).

Following the abandonment potential as a function of time (Fig. 2), in both solutions, shows that they have different behaviors. Indeed, we notice that:

The $\mathrm{Ca}(\mathrm{OH})_{2}$ solution: in the first hour of immersion, Ecorr decreases slightly which means that there is an attack of the metal, but Ecorr increases considerably more quickly with time and varies between $-0.54 \mathrm{~V}$ to $-0.47 \mathrm{~V}$ for an immersion time of $13 \mathrm{~h}$ and reaches a stationary value after $18 \mathrm{~h}$. This increase reflects the formation of a protective oxides layer on the surface of the steel which continues to evolve after $18 \mathrm{~h}$. According to El Haleem et al (2010-a) the value of the corrosion potential of a mild steel becomes increasingly noble (increasingly anodic value), reflecting the evolution in thickness and composition of the passive layer formed on the surface during the immersion time.

- The $\mathrm{Ca}(\mathrm{OH})_{2}$ solution with $0.5 \mathrm{M}$ of $\mathrm{CaCl}_{2}$ : an optimization of the potential for the first two immersion hours, this behavior can be associated with the formation of a layer of surface protective corrosion product, at the end of the third immersion hour, a displacement of the potential towards more negative values in the simulating solution which stabilizes at $-0.56 \mathrm{~V}$ after $18 \mathrm{~h}$ of immersion. This evolution of the potential is generally associated with a continuous dissolution of the material in the study medium (El Haleem et al., 2010-b). 


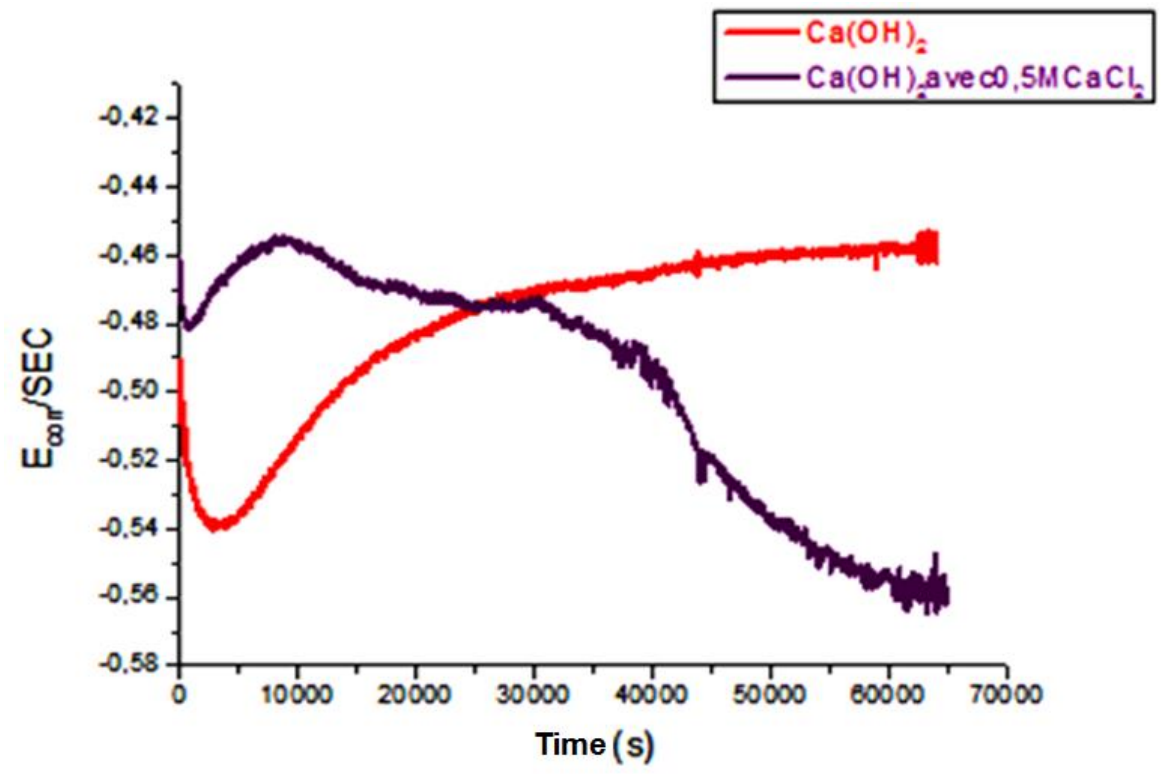

Fig. 2. Evolution of the corrosion potential in the two simulating solutions of concrete $\mathrm{Ca}(\mathrm{OH})_{2}+\mathrm{Ca}(\mathrm{OH})_{2}$ with $0.5 \mathrm{M}$ of $\mathrm{CaCl}_{2}$

\subsection{Influence of the agitation speed in $\mathrm{Ca}(\mathrm{OH})_{2}$ solution}

\subsubsection{Polarization curves}

In order to study the agitation effect of the medium on the electrochemical behavior of the steel E24, we have plotted polarization curves in the simulating solution $\mathrm{Ca}(\mathrm{OH})_{2}$ (Fig.3) with and without agitation in order to determine the electrochemical parameters such as the polarization resistance $\mathrm{Rp}$, the corrosion intensity (Icorr), the corrosion potential (Ecorr), the passivation step (Q passivation) and the corrosion speed.

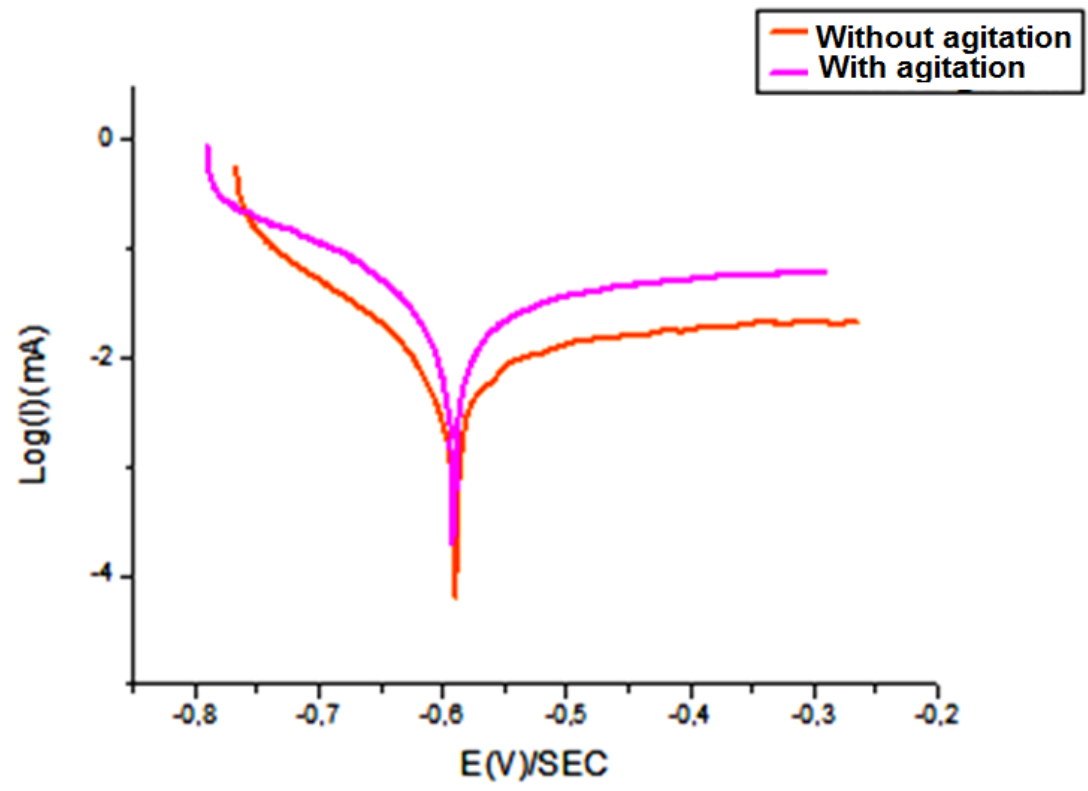

Fig. 3. Polarization curves of the steel $\mathrm{E} 24$ in $\mathrm{Ca}(\mathrm{OH}) 2$ solution with and without agitation. 


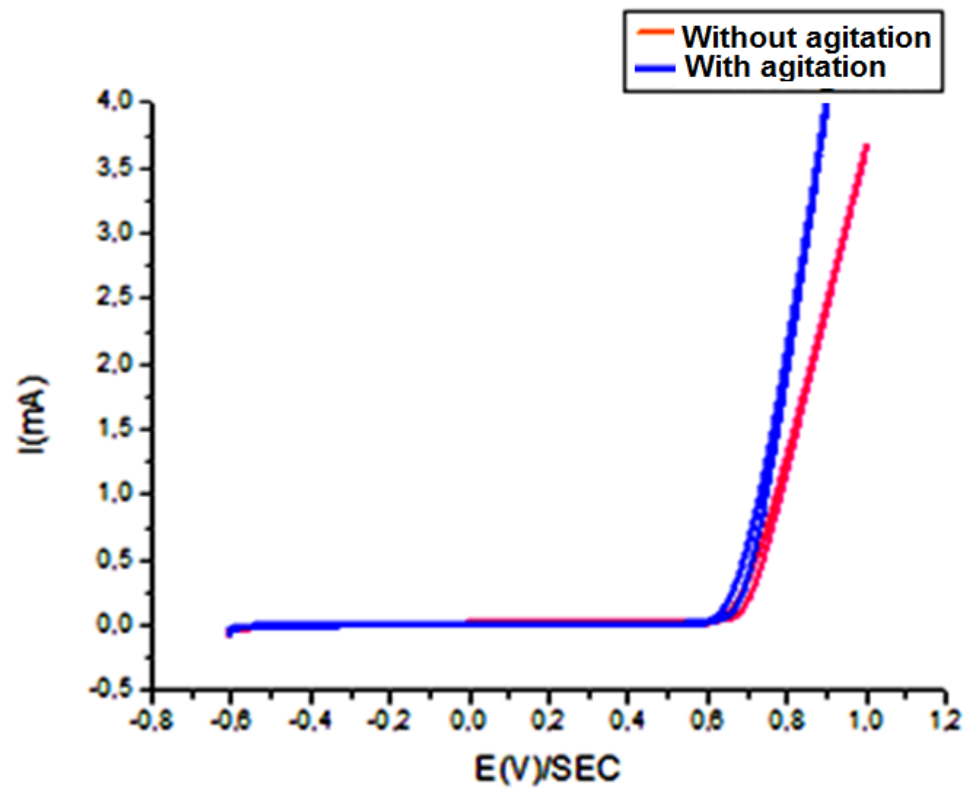

Fig. 4. Cyclic polarization in $\mathrm{Ca}(\mathrm{OH}) 2$ solution agitated and non-agitated.

The test parameters are: Scanning speed: $30 \mathrm{mV} / \mathrm{min}$ for the polarization resistance curves, 60 $\mathrm{mV} / \mathrm{min}$ for the Tafel curves and $120 \mathrm{mV} / \mathrm{min}$ for the cyclic polarization curves (these values correspond to the stationary state of the system).

- Potential range (abscissa): $-250 \mathrm{~V}$ to $+250 \mathrm{~V} / \mathrm{ECS}$ for the Tafel curves.

- $100 \mathrm{mV}$ to $1200 \mathrm{mV} / \mathrm{SCE}$ for the cyclic polarization curves.

The relative values for each case (without agitation, with agitation) are presented in Table 2.

Table 2. Electrochemical parameters determined from linear and cyclic polarization curves in the simulator solution.

\begin{tabular}{|c|c|c|c|c|c|c|c|}
\hline $\begin{array}{c}\text { Electrochemic } \\
\text { al parameters }\end{array}$ & $\begin{array}{c}\mathrm{Rp} \\
(\mathrm{Ohm})\end{array}$ & $\begin{array}{c}\text { Ecorr } \\
(\mathrm{mV})\end{array}$ & $\begin{array}{c}\text { Icorr } \\
(\mu \mathrm{A} / \mathrm{cm} 2)\end{array}$ & $\begin{array}{c}\beta \mathrm{a} \\
(\mathrm{mV})\end{array}$ & $\begin{array}{c}\beta \mathrm{c} \\
(\mathrm{mV})\end{array}$ & $\begin{array}{c}\mathrm{Q} \\
(\mathrm{mA} . \mathrm{V})\end{array}$ & $\begin{array}{c}\mathrm{C}=\mathrm{Q} / \mathrm{Icorr} \\
(\mathrm{V})\end{array}$ \\
\hline $\begin{array}{c}\text { Without } \\
\text { agitation }\end{array}$ & 7590 & $-590,532$ & 7,075 & 356,3 & 125 & 1,169 & 165,229 \\
\hline With agitation & 12150 & $-591,077$ & 28,166 & 670,9 & 181,3 & 1,949 & 69,196 \\
\hline
\end{tabular}

Figs. 3 and 4 show the polarization curves for the steel E24 plotted in the $\mathrm{Ca}(\mathrm{OH})_{2}$ solution agitated and non-agitated. In the cathodic domain, when the two curves are plotted from the corrosion potential Ecorr, a pseudo-plateau is observed around $-0.5 \mathrm{~V} /$ SCE due to the reduction of oxygen. Then, from: $-0.5 \mathrm{~V} / \mathrm{SCE}$, the cathode current density increases for both curves. This behavior can be explained by the contribution of the reduction of the oxide film formed during the tests (Byfors, 1987). Thus, we can say that during the cathodic plot the oxides are reduced and the surface becomes totally active for the reduction of the oxygen. In the anodic domain, a plateau of passivity is observed for both curves, but from the value of the rupture potential which is greater in the agitated solution than in the non-agitated solution and the increase in the density values of current for a more agitated solution than the increase in the non-agitated solution we can explain this behavior by the rupture of the passive film and the development of pitting in both cases (Bertolini et al., 2004). But, the rupture is more rapid in the agitated solution, this shows that the corrosion products adhere hardly at the metallic surface for the agitated solutions and this is demonstrated by the value of the compaction index of the passive layer. 


\subsubsection{Electrochemical impedance measurement}

In our study, the impedance spectra were measured at the corrosion potential with a frequency sweep of $100 \mathrm{kHz}$ to $10 \mathrm{mHz}$ at 10 points per decade and a modulation signal amplitude of 10 $\mathrm{mV}$. The modeling of the spectra was carried out by the software "ZView" using the equivalent electrical circuit (CEE) method.

The electrochemical impedance diagrams were plotted after the linear polarization resistance curves. Fig. 5 (a) shows the diagram in the complex plane (Nyquist diagrams) for an agitated and non-agitated $\mathrm{Ca}(\mathrm{OH})_{2}$ solution.

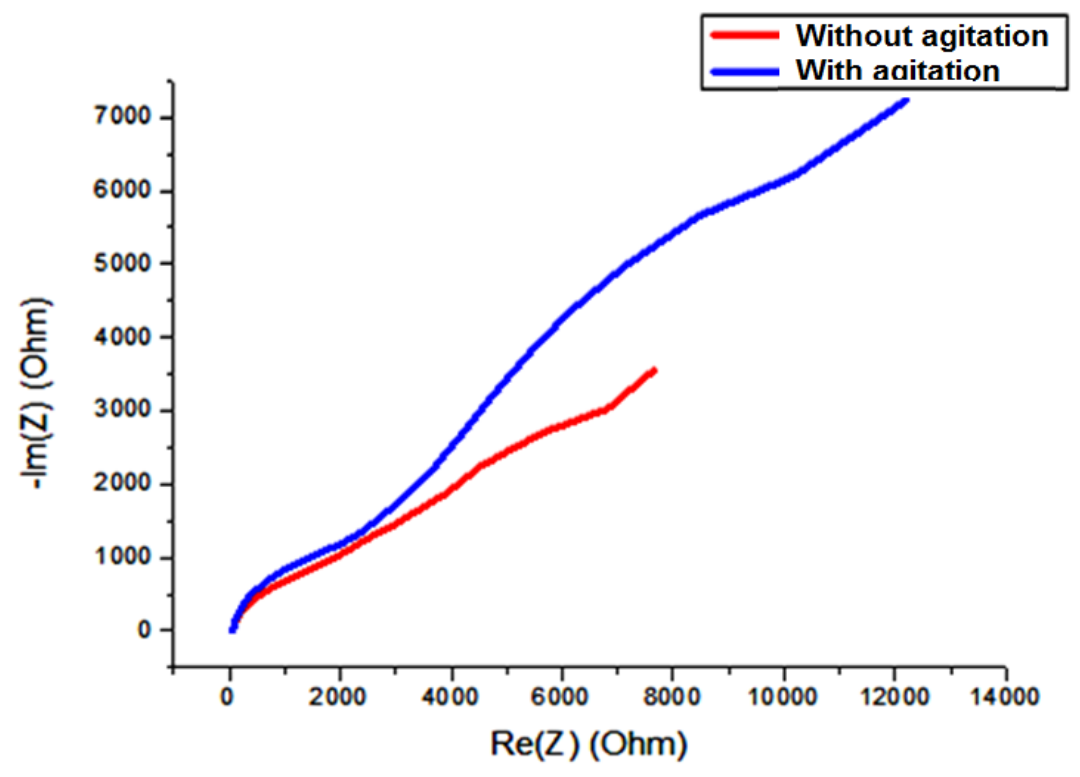

(a)

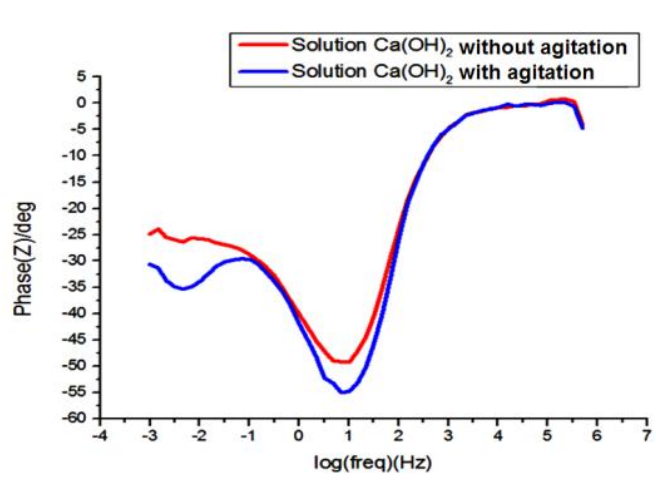

(b)

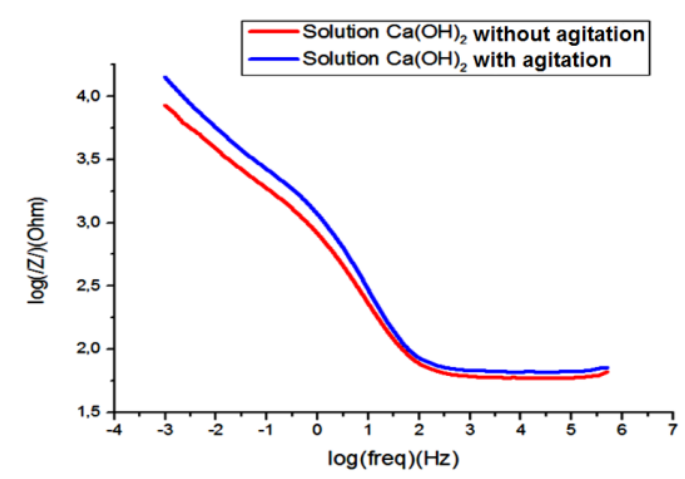

(c)

Fig. 5. Impedance diagrams of the steel $\mathrm{E} 24$ in $\mathrm{Ca}(\mathrm{OH})_{2}$ solution $3 \mathrm{~g} / \mathrm{l}$, plotted in agitated and non-agitated solution. (a) Nyquist diagrams, (b) Bode representation of the phase and (c) imaginary part of impedance as a function of frequency.

Fig. 6 shows the equivalent circuit proposed to simulate the impedance diagrams in order to better understand the behavior of the steel. In this equivalent circuit, Re and Rf represent respectively the resistance of the electrolyte and the resistance of the passive film (the passive layer deposited on the surface of the electrode). The equivalent circuit is complemented by a constant phase element (CPE). It is often very difficult to match the model to the experimental 
data. Indeed, the acquisition of low frequency points is sensitive to variations in the potential, particularly related to the phenomena of passivation/repassivation of the steel.

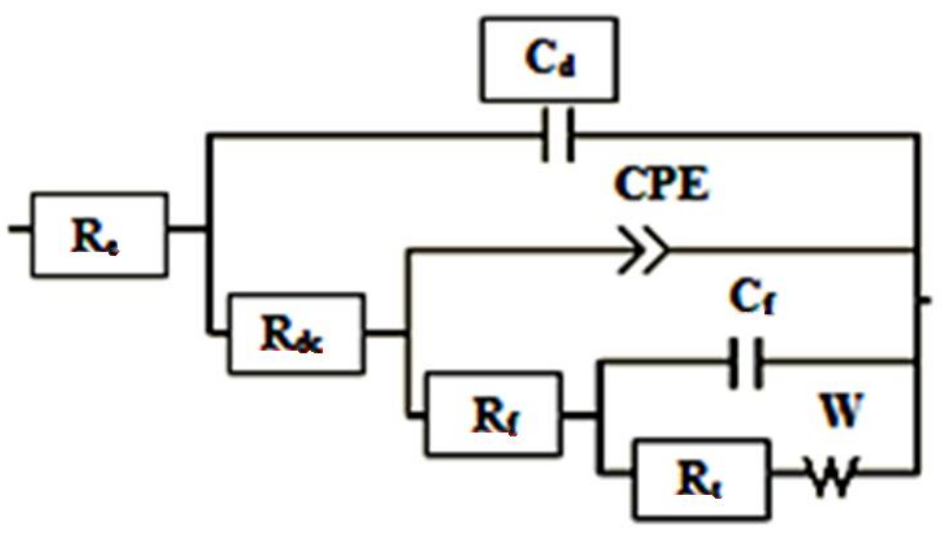

Fig. 6. Equivalent electrical circuit describing a metal-passive layer-electrolysis interface.

The different diagrams obtained (Fig. 5 (a)) have the same shape whatever the potential and they have a capacitive loop with a large diameter characteristic of a passive layer. All the diagrams overlap but show a slight slip in frequency when the solution becomes agitated. These results show that the electrochemical behavior of the steel is similar to Ecorr and to an anodic potential belonging to the passive field. Indeed, the diameter of the capacitive loop decreases in the non-agitated solution compared with the agitated solution, translating the less protective nature of the oxides layer formed, and the kinetics of dissolution of the metal.

The Bode representation of the phase (Fig. 5 (b)) reveals the presence of a single time constant whatever the potential. The representation of the imaginary part of the impedance as a function of the frequency in logarithmic coordinates (Fig. 5 (c)) is a straight line with a slope lower than 1 in absolute value in the low frequency domain and a stability in high frequencies, bringing out a CPE behavior. In the case of an oxide layer, the CPE behavior is generally attributed to a normal distribution of time constants induced by a significant variation in resistivity within the film (Longuet P, 1973). For this purpose, we may say that the CPE parameters are related to properties of the oxide layer, which is translated by a reduction in the thickness of the protective layer in the non-agitated $\mathrm{Ca}(\mathrm{OH})_{2}$ solution compared with an agitated solution. According to the results obtained in the $\mathrm{Ca}(\mathrm{OH})_{2}$ solution with and without agitation we can conclude that the measurements are more reliable and significant in the agitated solutions better than in the nonagitated solutions. Therefore, for our tests carried out to study the influence of the other parameters on the electrochemical behavior of the structural steel E24 are carried out with a moderate agitation speed of $40 \mathrm{rpm}$.

\subsection{Study of the effect of chlorides}

In this study, we added different levels of calcium chlorides in the calcium hydroxide solution. The tests were carried out in the presence of concentrations ranging between $0.01-0.5 \mathrm{M}$ of calcium chloride with a moderate agitation speed equal to $40 \mathrm{rpm}$.

\subsubsection{Polarization curves}

The effect of chlorides is more important. The corrosion potential is displaced to more anodic values (Fig. 7), the anodic currents are higher and the hysteresis is increased with increasing chloride concentrations.

In the case of a solution without addition of chloride, we notice that the hysteresis is very low; there is no attack of the metal when it is immersed in the solution, but we witness the formation of a very fine protective layer. However, the current densities (Icorr) increase as the 
concentrations of the chlorides increase with a decrease in the polarization resistance as well as an increase in the corrosion speed (Table3), which explains the deterioration of the passive film formed at the surface of the electrodes and the high aggressiveness of the chloride ions (Longuet, 1973; Longuet et al., 1973).

In the anode domain, it should be noted that the electrochemical process at the steel-solution interface is controlled by pure activation kinetics. The extrapolation of the Tafel lines to the corrosion potential makes it possible to calculate the corrosion speed. The anodic plateau is more extensive when the amount of chlorides decreases.

The cyclovoltamograms plotted in the range of $-100 \mathrm{mV}$ to $1200 \mathrm{mV} /$ SCE (FIG. 7) show an increase in hysteresis with the increase in $\mathrm{Cl}$ - content which indicates a strong degradation of the metal. The increase in the value of the oxidation peak current is due to the conversion of ferrous hydroxide $(\mathrm{Fe}(\mathrm{OH}) 2)$ to ferric hydroxide $(\mathrm{FeOOH})$.

The mechanism of corrosion takes place according to the following reactions (Ghods et al., 2009):

- In the anode zone:

$\mathrm{Fe} \rightarrow \mathrm{Fe}^{2+}+2 \mathrm{e}^{-}$

- In the cathode zone:

$2 \mathrm{H}_{2} \mathrm{O}+\mathrm{O}_{2}+4 \mathrm{e}^{-} \rightarrow 4 \mathrm{OH}^{-}$

In the second step of the corrosion process, the dissolved metallic ion $(\mathrm{Fe} 2+)$ reacts with the hydroxyls to form a precipitate which covers the steel according to the reaction:

$\mathrm{Fe}^{2+}+2 \mathrm{OH}^{-}+\mathrm{FeOH}_{2}$

In a sound concrete, which means if the $\mathrm{pH}>11$ and in the total absence of chlorides, we notice the formation of $\mathrm{FeOOH}$ protective layer according to the reaction?

$\mathrm{Fe}(\mathrm{OH})_{2} \rightarrow \mathrm{FeOOH}+\mathrm{H}^{+}+\mathrm{e}^{-}$

In the presence of the chlorides, the covering product no longer becomes leak-proof, and the steel corrodes following the sequence of the following reactions:

$$
\begin{aligned}
& \mathrm{FeOOH}+3 \mathrm{H}^{+} \rightarrow \mathrm{Fe}^{3+}+2 \mathrm{H}_{2} \mathrm{O} \\
& \mathrm{Fe}^{3+}+3 \mathrm{Cl}^{-} \rightarrow \mathrm{FeCl}_{3} \\
& \mathrm{Fe}+3 \mathrm{Cl}^{-} \rightarrow \mathrm{FeCl}_{3}^{-}+2 \mathrm{e}^{-} \\
& \mathrm{FeCl}_{3}^{-}+2 \mathrm{OH}^{-} \rightarrow \mathrm{Fe}(\mathrm{OH})_{2}+3 \mathrm{Cl}^{-}
\end{aligned}
$$

When the concentration of chloride ions is lower than that of the hydroxyl ions, stable ferrous hydroxide is formed, on the other hand, when it is higher, the hydroxide formed is unstable. An intermediate compound is formed, which is green rust $\left[2 \mathrm{Fe}(\mathrm{OH})_{2}, \mathrm{FeOHCl}, \mathrm{Fe}(\mathrm{OH})_{2} \mathrm{Cl}\right]$, which converts to lepidocrocite (hydrated ferric oxide $\mathrm{fe}_{2} \mathrm{O}_{3}, \mathrm{H}_{2} \mathrm{O}$ ) containing chlorine according to the reaction below (Diamond, 1975)

$2\left[2 \mathrm{Fe}(\mathrm{OH})_{2}, \mathrm{FeOHCl}\right] \rightarrow\left[2 \mathrm{Fe}(\mathrm{OH})_{2}, \mathrm{FeOHCl}, \mathrm{Fe}(\mathrm{OH})_{2} \mathrm{Cl}\right]+\mathrm{Fe}(\mathrm{OH})_{2}+\mathrm{FeOH}$

Hydroxyde II Rouille verte I Hydroxyde I

This, explains the results observed on our polarized samples, a green product covers the surface of the steel and transforms into black. Therefore, we can conclude that the addition of the different quantities of $\mathrm{CaCl} 2$ in the solution increased the probability of corrosion initiation for structural steel E24. For the study the influence of chemical parameters on the electrochemical behavior to the corrosion of the structural steel E24 we use a $\mathrm{Ca}(\mathrm{OH})_{2}$ solution with a concentration of $3 \mathrm{~g} / \mathrm{l}$ with $0.5 \mathrm{M}$ of $\mathrm{CaCl}_{2}$. 
The polarization and cyclo-voltamogram curves of the steel E24 in the calcium hydroxide $\left(\mathrm{Ca}(\mathrm{OH})_{2}\right)$ solution in the presence of the different quantities of $\mathrm{CaCl}_{2}$ and the electrochemical parameters extracted from these curves are shown in figures and the table below:
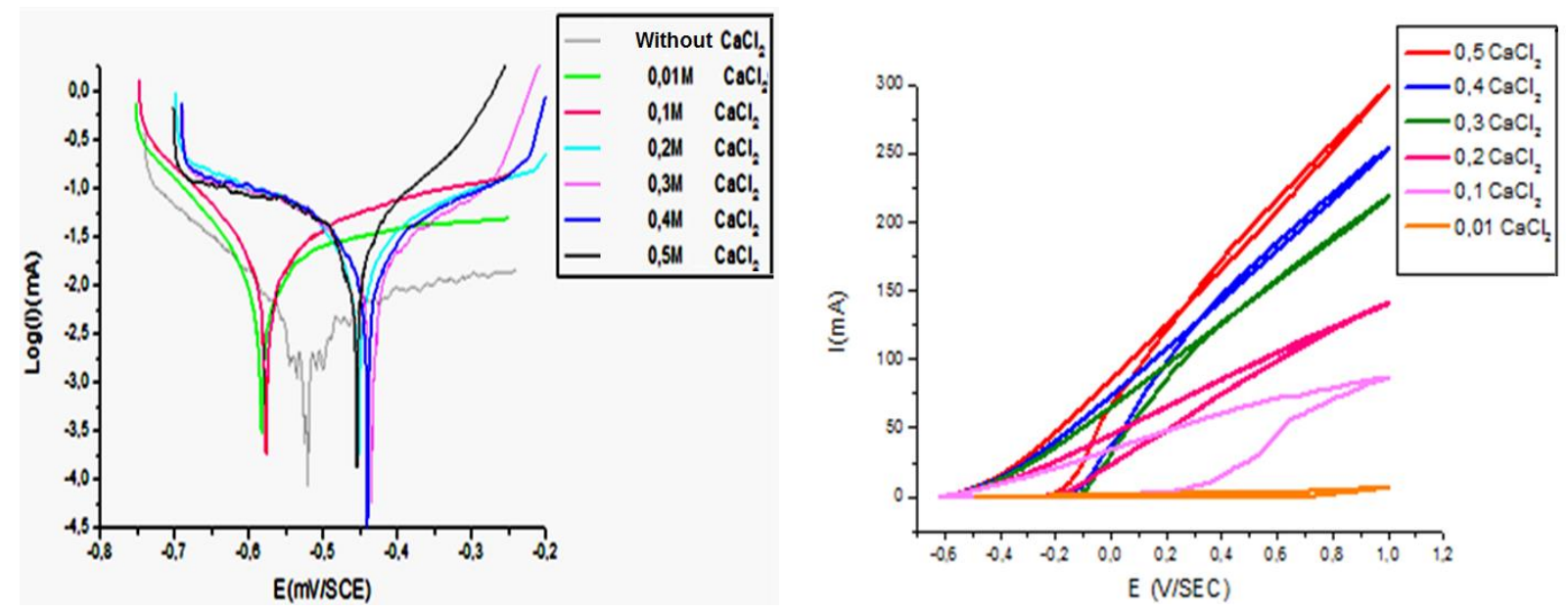

Fig. 7. Polarization curves of the structural steel $\mathrm{E} 24$ in the $\mathrm{Ca}(\mathrm{OH})_{2}$ solution with different concentrations of $\mathrm{CaCl}_{2}$.

Table 3. Electrochemical parameters determined from linear and cyclic polarization curves with different concentration of $\mathrm{CaCl}_{2}$

\begin{tabular}{|c|c|c|c|c|c|c|c|}
\hline $\begin{array}{c}\text { Electrochemical } \\
\text { parameters }\end{array}$ & ${ }^{2}$ & & & & & & \\
\hline $\begin{array}{c}\text { Concentrations of } \\
\mathrm{CaCl} 2\end{array}$ & Ohm & $(\mathrm{mV})$ & $\mu \mathrm{A} / \mathrm{cm} 2$ & $(\mathrm{mV})$ & $(\mathrm{mV})$ & (mA.V) & 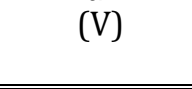 \\
\hline $\begin{array}{c}\text { Without the } \\
\text { addition of } \mathrm{CaCl}_{2}\end{array}$ & 7909 & $-522,104$ & 4,335 & 435,2 & 148,1 & 1,989 & 458,824 \\
\hline With 0.01 of $\mathrm{CaCl}_{2}$ & 4024 & $-582,213$ & 10,895 & 263,7 & 107,6 & 5,16 & 473,611 \\
\hline With 0.1 of $\mathrm{CaCl}_{2}$ & 1579 & -577 & 18,714 & 264,7 & 127,6 & 109,32 & 5841,616 \\
\hline With 0.2 of $\mathrm{CaCl}_{2}$ & 1446 & $-453,77$ & 30,968 & 314,5 & 275,8 & 194,321 & 6274,897 \\
\hline With 0.3 of $\mathrm{CaCl}_{2}$ & 715 & $-433,99$ & 19,07 & 216,4 & 195,5 & 297,031 & 15575,826 \\
\hline With 0.4 of $\mathrm{CaCl}_{2}$ & 520 & $-440,119$ & 29,467 & 294,2 & 269,2 & 342,371 & 11618,794 \\
\hline With 0.5 of $\mathrm{CaCl}_{2}$ & 446 & -465 & 43,38 & 178,3 & 335,8 & 406,453 & 9369,594 \\
\hline
\end{tabular}

\subsubsection{Electrochemical impedance measurements}

The study of the corrosion mechanism of the reinforcing steel E24 in the saturated $\mathrm{Ca}(\mathrm{OH})_{2}$ solution in the presence of different concentrations of $\mathrm{CaCl}_{2}$ was carried out by electrochemical impedance measurements, with a free corrosion potential. The impedance diagrams recorded for these concentrations are shown in Figs 8 and 9. 


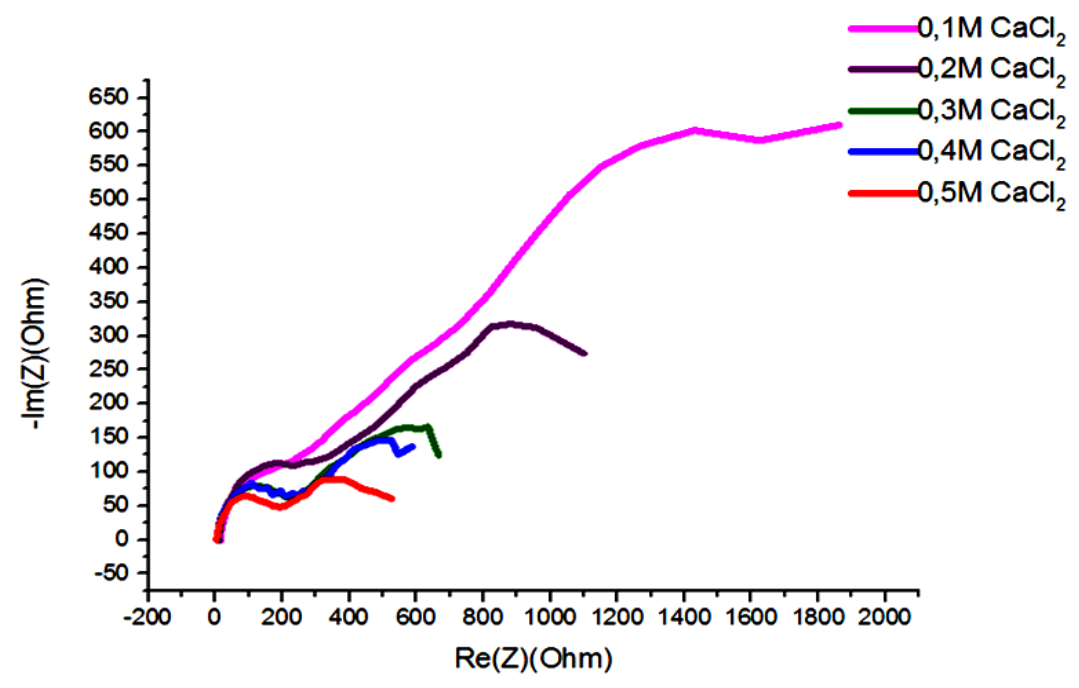

Fig. 8. Impedance diagrams (Nyquist plane) of the reinforcement steel E24 in a $\mathrm{Ca}(\mathrm{OH})_{2}$ solution with different concentrations of $\mathrm{CaCl}_{2}$

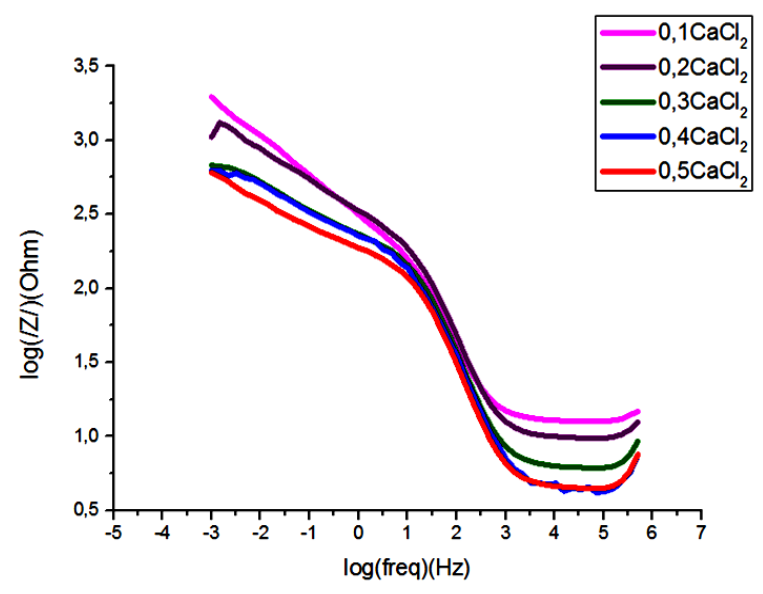

(a)

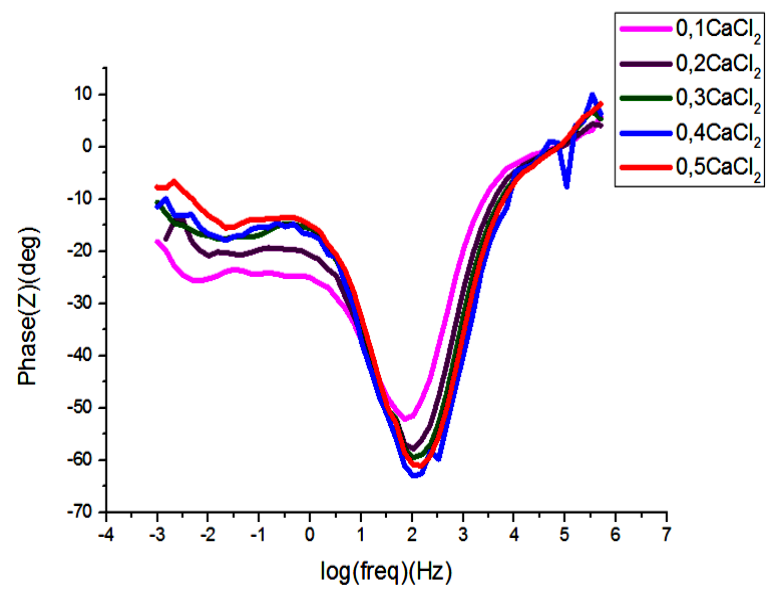

(b)

Fig. 9. Impedance diagrams (Bode plane) of the reinforcement steel E24 in a solution of $\mathrm{Ca}(\mathrm{OH}) 2$ with different concentrations of $\mathrm{CaCl}_{2}$.

The diagrams are composed of two capacitive loops: one with a smaller diameter in high frequency (HF) and one with a larger diameter in low frequency (BF) (Fig. 8). The size of the first loop increases progressively with the decrease in concentration of chloride ions, this loop corresponds to a charge transfer phenomenon which confirms a lot the aggressive effect of chloride ions. When the concentration of chlorides increases we notice the appearance of a second loop, which is attributed to the phenomenon of initiation of diffusion.

On the Bode diagrams (Fig. 9a), we observe the presence of a resistive region at high frequencies. The polarization resistance $\mathrm{Rp}$ decreases with the increase in chloride concentrations (Table 03) but it decreases significantly at a concentration of $0.3 \mathrm{M}$ and higher. In this case we can say that at low concentrations the steel is able to resist and the oxide layer plays a little bit the role of a protective layer, but beyond the concentration of $0.2 \mathrm{M}$ there is an attack of chloride ions at the complete surface of the electrode and the corrosion resistance of the steel becomes very low for these concentrations. 
As for the variation of the phase as a function of the frequency (Fig. 9b), we notice that the phase angle reaches maximum values at high concentrations, so, for the different chloride concentrations two time constants have been observed.

The interpretation of the electrochemical impedance spectroscopy (SIE) diagrams makes it possible to determine the different processes that take place at the electrode (Byfors et al., 1986). In some cases, especially when the time constants of the elementary steps are poorly decoupled, it is necessary to model the impedance of the electrochemical system by that of an equivalent electrical circuit.

The analysis of the impedance data of Figs. 8 and 9 from the equivalent circuit of Fig. 10, using the Z-View software, makes it possible to determine the CPE parameter values, the charge transfer resistance Rt as well as the resistance of the electrolyte Re. Thus, the values obtained are presented in Table 4 :

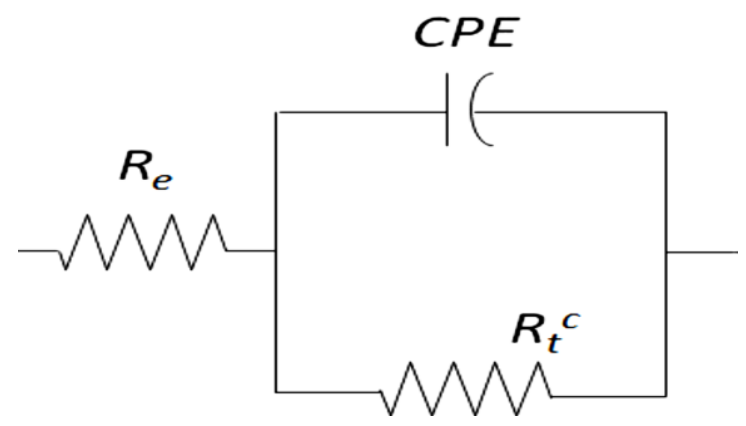

Fig. 10. Modeled equivalent circuit of the electrode/electrolyte interface.

Table 4. Electrochemical parameters deducted from impedance diagrams.

\begin{tabular}{|c|c|c|c|c|c|}
\hline CC de CaCl2 & $\begin{array}{c}\mathrm{Re} \\
\left(\mathrm{Ohm} . \mathrm{cm}^{2}\right)\end{array}$ & $\begin{array}{c}\mathrm{Rt} \\
\left(\mathrm{Ohm} . \mathrm{cm}^{2}\right)\end{array}$ & $\alpha$ & $\begin{array}{c}\mathrm{Q} \\
\left(\Omega^{-1} \mathrm{~cm}^{-2} \mathrm{~S}^{\alpha}\right)\end{array}$ & $\begin{array}{c}\mathrm{CPE} \\
\left(\mu \mathrm{F} / \mathrm{cm}^{2}\right)\end{array}$ \\
\hline \hline $0.1 \mathrm{M}$ & 13,06 & 1435 & 0.83 & $1.9 \times 10^{-3}$ & 1075 \\
\hline $0.2 \mathrm{M}$ & 9,45 & 1317 & 0.82 & $1.6 \times 10^{-3}$ & 1135 \\
\hline $0.3 \mathrm{M}$ & 10,23 & 985 & 0.71 & $1.2 \times 10^{-3}$ & 1532 \\
\hline $0.4 \mathrm{M}$ & 8,73 & 743 & 0.71 & $1.2 \times 10^{-3}$ & 1561 \\
\hline $0.5 \mathrm{M}$ & 6,81 & 684 & 0.71 & $1.2 \times 10^{-3}$ & 1585 \\
\hline
\end{tabular}

The impedance of a CPE is given by:

$Z_{C P E}=\frac{1}{Q(i \omega)^{\alpha}}$

It brings out two parameters, $\mathrm{Q}$ and $\alpha$, independent of the frequency. A CPE behavior can be attributed to a distribution of time constants either along the surface of the electrode (surface distribution) or along the normal axis to the electrode surface (normal distribution). A surface distribution may come from surface heterogeneities (grain boundaries, crystalline faces, etc.) or non-uniform distributions of current and potential induced by the electrode geometry, whereas a normal distribution can be generated by a porous electrode or a variation of conductivity within surface layers such as oxide films (Rothstein et al., 2002).

In the case of a R // CPE circuit, the parameters of the CPE $\alpha$ and $Q$ can be graphically estimated according to the method presented by Orazem et al. (2006) $\alpha$ corresponds to the absolute value of the slope of the curve $\log |\mathrm{Z}|$ vs $\log \mathrm{f}$ :

$\alpha=\left|\frac{d \log |Z(f)|}{d \log f}\right|$ 
and $Q$ is obtained from $\alpha$ as follows:

$Q=-\frac{1}{Z(f)(2 \pi f)^{\alpha}} x \sin \left(\frac{\alpha \pi}{2}\right)$

The values of $\alpha$ and $Q$ obtained by adjustment correspond to those usually measured for oxide layers ; the passive layer type (Diamond, 1981). The value of $Q$ decreases as the concentration increases, which is consistent with an increase in the thickness of the dox oxide layer with an increase in concentration. Similarly, in the case of CPE behavior, a decrease in Q corresponds to an increase in dox. Thus, the increase in the concentration of the $\mathrm{Cl}$ - ions leads to the decrease in the transfer resistance Rt, which explains the decrease in the corrosion resistance.

\subsection{Study of the effect of the pH of the medium}

The polarization curves plotted in a carbonate medium with $0.5 \mathrm{M}$ of $\mathrm{CaCl}_{2}$ for studying the influence of the $\mathrm{pH}$ are shown in Fig. 11. The electrochemical characteristics deduced from these polarization curves by the Tafel line plots and the linear polarization curves are summarized in Table 5.

The plotting of these curves at different $\mathrm{pH}$ values (pH varies from 06-08-10 and 11) was carried out with a sweep speed of $60 \mathrm{mV} /$ min between $\pm 250 \mathrm{mV} /$ SCE. We should note that for all the tests a waiting period of $15 \mathrm{~min}$ after immersion corresponds to the time of formation and stability of the electric double layer was respected, while maintaining a continuous and moderate agitation of the medium throughout the test period (See paragraph 5.3.b).

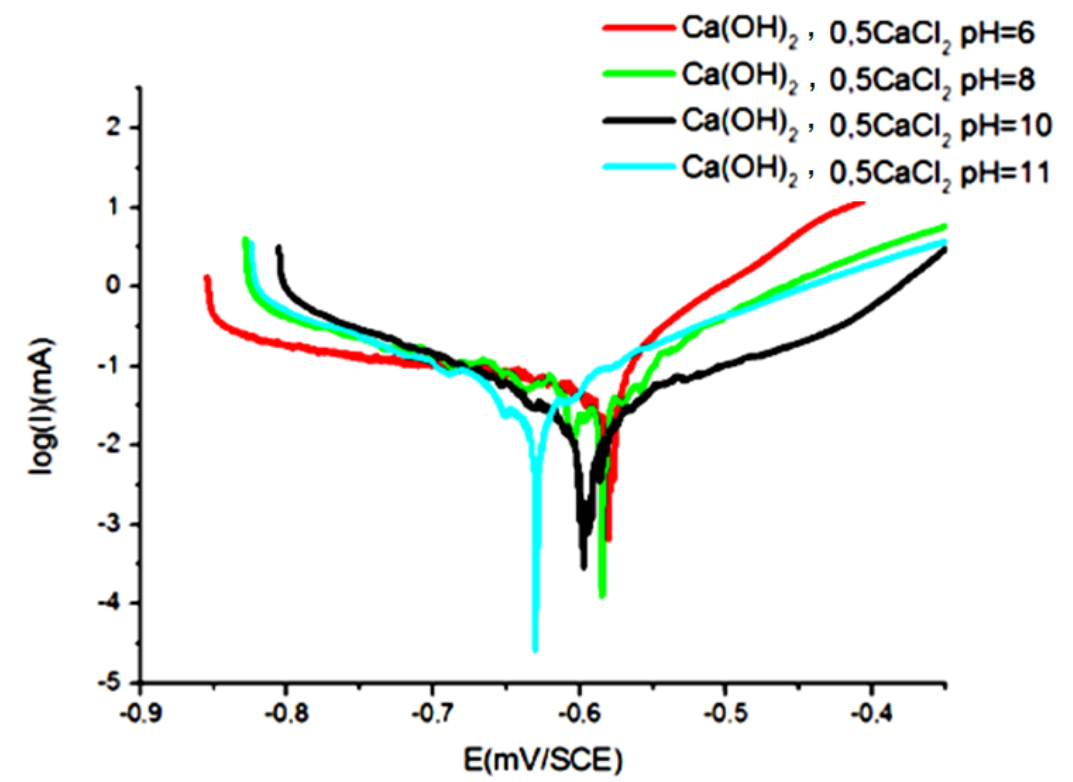

Fig. 11. Tafel curves deduced the influence of the $\mathrm{pH}$ of the medium.

Table 5. Electrochemical parameters deducted from polarization curves.

\begin{tabular}{|c|c|c|c|c|c|}
\hline $\begin{array}{c}\text { Electrochemical } \\
\text { parameters }\end{array}$ & $\begin{array}{c}\mathrm{Rp} \\
(\mathrm{Ohm})\end{array}$ & $\begin{array}{c}\text { Ecorr } \\
(\mathrm{mV})\end{array}$ & $\begin{array}{c}\text { Icorr } \\
(\mu \mathrm{A} / \mathrm{cm} 2)\end{array}$ & $\begin{array}{c}\beta \mathrm{a} \\
(\mathrm{mV})\end{array}$ & $\begin{array}{c}\beta \mathrm{c} \\
(\mathrm{mV})\end{array}$ \\
\hline \hline $\mathrm{pH}$ of the medium & 361 & $-580,428$ & 51,931 & 55,1 & 398,1 \\
\hline $\mathrm{pH}=6$ & 474 & $-585,626$ & 51,480 & 94,2 & 269 \\
\hline $\mathrm{pH}=8$ & 522 & $-597,821$ & 26,726 & 166,8 & 144,6 \\
\hline $\mathrm{pH}=10$ & 620 & -630 & 38,113 & 121,3 & 154,1 \\
\hline
\end{tabular}

- Hoar and Hurlen in 1959 showed an influence of $\mathrm{pH}$ on the iron dissolution reaction and found that the kinetics of this reaction were of order 1 compared with the concentration 
of hydroxide ions (Drouin et al., 2011). The numerous studies carried out subsequently led their authors to propose a mechanism of either catalytic or non-catalytic type (Perier et al., 2013).

After a first common hydrolysis step:

$\mathrm{Fe}+\mathrm{H}_{2} \mathrm{O} \rightarrow(\mathrm{FeOH})_{a d s}+\mathrm{H}^{+}+e^{-}$

The following steps diverge according to the mechanism:

- Catalytic mechanism:

$\mathrm{Fe}+(\mathrm{FeOH})_{a d s} \rightarrow \mathrm{Fe}(\mathrm{FeOH})_{a d s}$

$\mathrm{Fe}(\mathrm{FeOH})_{a d s}+\mathrm{OH}^{-} \rightarrow \mathrm{FeOH}^{+}+(\mathrm{FeOH})_{a d s}+2 e^{-}$

- Non-catalytic mechanism:

$\mathrm{Fe}(\mathrm{FeOH})_{a d s} \rightarrow \mathrm{FeOH}^{+}+e^{-}$

$\mathrm{FeOH}^{+}+\mathrm{H}^{+} \rightarrow \mathrm{Fe}^{2+} \mathrm{aq}+\mathrm{H}_{2} \mathrm{O}$

In our case, the examination of the polarization curves obtained for the reinforcing steel (Fig.8) shows a displacement of the corrosion potential towards more cathodic potentials and, in contrast, a decrease in the density of the Icorr current can be explained by an effect of the accumulation of corrosion products on the surface of the electrode. In fact, these corrosion products are more and denser and less soluble when the $\mathrm{pH}$ decreases. The corrosion speeds measured translating a greater corrosion at all $\mathrm{pH}$ values and clearly higher when the $\mathrm{pH}$ of the medium is low which indicates that the corrosion resistance decreases significantly when the $\mathrm{pH}$ of the medium reaches low values. We also notice that the Rp values (Table 4) increase as the Icorr values decrease. These results are consistent because the resistance $\mathrm{Rp}$ is inversely proportional to Icorr and can be obtained via the Stern-Geary relation. These results are consistent with previous work by DUPRAT and DABOSI (Dupart and Dabosi, 1981) which show low corrosion resistance in this $\mathrm{pH}$ range.

However, the observation of the surface state at the end of our electrochemical tests reveals an important layer of corrosion product with a deep attack under that one when the $\mathrm{pH}$ decreases, this examination would confirm an increase in corrosion when the $\mathrm{pH}$ decreases.

\section{Conclusion}

The consequences of the carbonation of concrete and the presence of chloride are frequently the cause of major degradations of concrete and reinforced concrete structures. This study shows the influence of calcium hydroxide solution $\mathrm{Ca}(\mathrm{OH})_{2}$ used as a simulating solution alone and with different concentrations of $\mathrm{CaCl}_{2}$ on the electrochemical corrosion behavior of reinforcing steel E24 using techniques electrochemical and stationary. The monitoring of the abatement potential as a function of time in the two solutions of saturated $\mathrm{Ca}(\mathrm{OH})_{2}$ and $\mathrm{Ca}(\mathrm{OH})_{2}$ in the presence of chloride ions after 18 hours of immersion shows that they behave differently, the $\mathrm{Ca}(\mathrm{OH})_{2}$ solution observed an increase in the value of the Ecorr and reached a stationary value after $18 \mathrm{~h}$. This increase reflects the formation of a protective oxide layer on the surface of the steel by in the solution of lime in the presence of $\mathrm{CaCl}_{2}$ we notice a displacement of the potential towards more negative values this evolution of the potential is generally associated with a continuous dissolution of the material in the study medium. Thus, in order to study the influence of chloride ions and to determine the critical concentration of the latter responsible for the corrosion initiation of steel, we have drawn linear and cyclic polarization curves and electrochemical impedance curves, observed on our polarized samples, shows the appearance of a green product covering the surface of the steel and turns into black. Therefore, we can conclude that adding the different amounts of $\mathrm{CaCl}_{2}$ in the solution increased the probability of corrosion initiation for structural steel. Thus the influence of the $\mathrm{pH}$ of the 
medium on the corrosion of our steel samples is studied because it constitutes a very important parameter to better understand the reactions of the dissolution of iron the results obtained by the plot of the curves of linear polarizing in the solution of calcium hydroxide with $0.5 \mathrm{M} \mathrm{CaCl}_{2}$ watches when the $\mathrm{pH}$ of the simulating solution decreases there is a deep attack and the formation of a large layer of product for this purpose it can be concluded that the rate of corrosion increases when the $\mathrm{pH}$ of the medium decreases.

\section{References}

Bertolini, L., Bernhard, E., Pietro, P., \& Rob, P. (2004). Corrosion of steel in concrete: prevention, diagnosis, repair. Bedin: Wiley- $\mathrm{VCH}$.

Byfors, K. (1987). Influence of silica fume and flyash on chloride diffusion and $\mathrm{pH}$ values in cement paste. Cement and Concrete research, 17(1), 115-130.

Byfors, K., Hansson, C. M., \& Tritthart, J. (1986). Pore solution expression as a method to determine the influence of mineral additives on chloride binding. Cement and Concrete Research, 16(5), 760-770.

Diamond, S. (1975). Long-term status of calcium hydroxide saturation of pore solutions in hardened cements. Cement and Concrete Research, 5(6), 607-616.

Diamond, S. (1981). Effects of two Danish flyashes on alkali contents of pore solutions of cement-flyash pastes. Cement and Concrete Research, 11(3), 383-394.

Drouin, B., Latour, G., \& Mohamed, H. (2011). More than 10 years successful field applications of FRP bars in Canada. In CDCC 2011, The 4th Int. Conf. on Durability and Sustainability of Fiber Reinforced Polymer (FRP) Composites for Construction and Rehabilitation.

Duprat, M., \& Dabosi, F. (1981). Corrosion inhibition of a carbon steel in 3\% $\mathrm{NaCl}$ solutions by aliphatic amino-alcohol and diamine type compounds. Corrosion, 37(2), 89-92.

El Haleem, S. A., El Aal, E. A., El Wanees, S. A., \& Diab, A. (2010-a). Environmental factors affecting the corrosion behaviour of reinforcing steel: I. The early stage of passive film formation in Ca (OH) 2 solutions. Corrosion Science, 52(12), 3875-3882.

El Haleem, S. A., El Wanees, S. A., El Aal, E. A., \& Diab, A. (2010-b). Environmental factors affecting the corrosion behavior of reinforcing steel II. Role of some anions in the initiation and inhibition of pitting corrosion of steel in $\mathrm{Ca}(\mathrm{OH}) 2$ solutions. Corrosion science, 52(2), 292-302.

Ghods, P., Isgor, O. B., McRae, G., \& Miller, T. (2009). The effect of concrete pore solution composition on the quality of passive oxide films on black steel reinforcement. Cement and Concrete Composites, 31(1), 2-11.

Kosmatka, S. H., Kerkhoff, B., Panarese, W. C., MacLeod, N. F., \& McGrath, R. J. (2004). Dosage et contrôle des mélanges de béton. Bulletin d'ingenierie EB101, Cement Association of Canada.

Longuet, P. (1973). La phase liquide du ciment hydraté, revue des Matériaux de Constructions et de Travaux Publics, section Ciments. pp 35-41.

Longuet, P., Peguin, P., Rubaud, M., \& Zelwer, A. (1973). Bases experimentales de l'etude electrochimique du comportement des metaux en presence di beton. Corrosion TPE, 2(3), 155-159.

Neville, A. M. (2000). Propriétés des bétons. Eyrolles.

Orazem, M. E., Pébère, N., \& Tribollet, B. (2006). Enhanced graphical representation of electrochemical impedance data. Journal of The Electrochemical Society, 153(4), B129-B136.

Perier, V., Chataigner, S., \& Pruvost, A. (2013). Comparaison de différentes armatures utilisées pour le renforcement du béton.. Bulletin des laboratoires de Ponts et Chaussées, pp 51- 62.

Rosenberg, A. C. M. H. (1989). Mechanisms of corrosion of steel in concrete. Materials science of concrete, 1, 285-316.

Rothstein, D., Thomas, J. J., Christensen, B. J., \& Jennings, H. M. (2002). Solubility behavior of Ca-, S-, Al-, and Si-bearing solid phases in Portland cement pore solutions as a function of hydration time. Cement and Concrete Research, 32(10), 1663-1671. 